ISSN: $2338-4794$

Vol.6. No. 3 Sept.- Des. 2018

\title{
PENGARUH MANAJEMEN HUBUNGAN PELANGGAN TERHADAP KEPUASAN KONSUMEN
}

\author{
Ellena Nurfazria Handayani ${ }^{1)}$ \\ 1) Dosen Universitas Darma Persada Jakarta \\ Alamat: Jalan Taman Malaka Selatan, Pondok Kelapa - Jakarta Timur \\ Email: ellena.nurfazria@fe.unsada.ac.id \\ Edwin Yudha Pratama ${ }^{2)}$ \\ 2) Mahasiswa Universitas Darma Persada Jakarta
}

\begin{abstract}
The purpose of this research is to know the influence of customer relationship management (CRM) consists of three independent variables: communication, commitment and quality of service towards customers' satisfaction at PT Indomobil Trada (Nissan) Radin Inten. This research is associative research with quantitative approach is done by using survey method through the distribution of a questionnaire to 120 respondents were selected using a non-probability sampling techniques. Data analysis technique used is multiple linear regression analysis with stepwise method. The research results showed that all the independent variables of the customer relationship management (CRM) have a positive and significant influence towards customer satisfaction. From the results of this research are expected to increase the company's customer relationship management with increasing commitment, communication and quality of service, so that it can increase customer satisfaction.
\end{abstract}

Keywords: Customer relationship management, customers' satisfaction

\section{PENDAHULUAN}

Indonesia merupakan salah satu negara dengan jumlah penduduk terbesar di dunia. tercatat pada tahun 2010-2015 pertumbuhan penduduk meningkat $1,38 \%$ pertahunnya (www.bps.go.id). Jumlah penduduk Indonesia pada tahun 2016 mencapai 255 juta jiwa. Jumlah penduduk Indonesia yang banyak menyebabkan banyaknya kegiatan ekonomi yang timbul karena adanya kebutuhan dan keinginan. Penduduk memiliki beraneka ragam cara dan perilaku dalam memenuhi kebutuhannya. Semakin berkembangnya perekonomian berdampak pada semakin banyak dan beraneka ragamnya kebutuhan. Keinginan juga mengalami pergeseran ke arah kebutuhan yang harus dipenuhi. Kebutuhan penduduk akhirnya memiliki beaneka ragam kategori mulai dari kebutuhan primer, sekunder hingga tersier. \begin{tabular}{lcrr}
\multicolumn{1}{c}{ Salah } & satu kebutuhan & yang \\
meningkat adalah kebutuhan & akan \\
transportasi. & Menurut data yang \\
bersumber dari www.kompasiana.com \\
menyatakan
\end{tabular} kendaraan bermotor roda dua saat ini sebesar 800 unit per bulan dan mobil sekitar 300 unit perbulan. Dari data tersebut dapat dikatakan bahwa kebutuhan masyarakat akan sarana transportasi cukup tinggi. Hal ini juga didorong oleh tingginya mobilitas masyarakat dalam beraktifitas sehari-hari, dimana mereka harus berpindah dari satu tempat ke tempat yang lain dan juga perilaku konsumtif yang mendorong masyarakat untuk memiliki kendaraan pribadi.

Berdasarkan pada data dari GAIKINDO (Gabungan Industi Kendaraan Bermotor Indonesia) penjualan mobil seluruh pabrikan di Indonesia dari bulan Januari-September 2017 mencapai 803.757 unit. Pasar mobil penumpang 
yang semakin meningkat membuat banyaknya perusahaan otomotif berlomba-lomba memasarkan produknya. Hal ini menimbulkan persaingan bisnis otomotif juga semakin meningkat baik dalam penjualan maupun dalam mempertahankan pelanggannya.

Dalam memasarkan mobil tentunya perusahaan juga sadar betul terhadap akan munculnya permintaan turunan dari pelanggan seperti permintaan pasca pembelian. Pelanggan berharap mobil yang dibelinya mendapatkan layanan perawatan yang terpercaya agar kondisi mobilnya tetap prima dan selalu siap digunakan untuk aktivitas sehari-hari. Untuk itu perusahaan menyediakan bengkel terpercaya sebagai tempat untuk melayani pelanggan dalam melakukan perawatan mobilnya. Bengkel sebagai tepat bertemunya langsung pelanggan dengan perusahaan memiliki peranan yang sangat penting. Selain sebagai tempat perawatan mobil, bengkel juga menjadi tempat untuk sarana promosi untuk memenangkan hati pelanggan dengan melalui pelayanan terbaik sehingga pelanggan merasa puas. Menurut Tjiptono (2008) pelanggan yang puas dapat memberikan beberapa manfaat seperti terciptanya hubungan yang harmonis antara perusahaan dan pelanggan, memberikan dasar yang baik bagi pembelian ulang dan terciptanya loyalitas pelanggan serta membentuk suatu rekomendasi dari mulut ke mulut yang menguntungkan bagi perusahaan.

Dalam dunia otomotif mobil ada banyak berbagai lembaga survei yang melakukan survei terhadap tingkat kepuasan pelanggan pasca pembelian mobil. Dalam survei faktor layanan bengkel menjadi faktor yang paling berpengaruh terhadap kepuasan pelanggan. Perusahaan-perusahaan otomotif yang beroperasi di area Asia Pasific, termasuk di Indonesia, menggunakan JD Power sebagai suatu lembaga independen yang melakukan survei terhadap kepuasan pelanggan.

Tabel 1. Perbandingan Indeks Kepuasan Pelanggan Indonesia Tahun 2015-2017

\begin{tabular}{cccccccc}
\hline \multirow{2}{*}{ No } & \multirow{2}{*}{ Brand } & \multicolumn{2}{c}{$\mathbf{2 1 0 5}$} & \multicolumn{2}{c}{$\mathbf{2 1 0 6}$} & \multicolumn{2}{c}{ 2017 } \\
& & CSI & Ranking & CSI & Ranking & CSI & Ranking \\
\hline 1 & Toyota & 764 & 3 & 769 & 1 & 774 & 2 \\
2 & Nissan & 756 & 7 & 767 & 2 & 756 & 9 \\
3 & Mitsubishi & 764 & 2 & 766 & 3 & 767 & 6 \\
4 & Daihatsu & 762 & 4 & 765 & 4 & 770 & 3 \\
5 & Datsun & 750 & 9 & 763 & 5 & 769 & 4 \\
6 & Honda & 762 & 5 & 760 & 6 & 768 & 5 \\
7 & Mazda & 769 & 1 & 759 & 7 & 774 & 1 \\
8 & Chevrolet & 759 & 6 & 759 & 8 & 763 & 7 \\
9 & Suzuki & 754 & 8 & 758 & 9 & 763 & 8 \\
\hline
\end{tabular}

Sumber : www.jdpower.com

Nissan sebagai salah satu perusahaan otomotif yang memasarkan produknya di Indonesia berusaha untuk menjaga kepuasan pelanggan. Dari tabel 1 diketahui bahwa kepuasan pelanggan
Nissan pada tahun 2015 menempati peringkat tujuh dan mengalami peningkatan drastis ke peringkat dua pada tahun 2016. Namun pada tahun 2017 kepuasan pelanggan mengalami 
penurunan yang cukup drastis ke peringkat sembilan.

Berdasarkan permasalahan yang diatas, yaitu index kepuasan pelanggan yang masih naik turun tidak sesuai dengan target maka peneliti tertarik untuk melakukan penelitian dengan judul "Analisis Pengaruh Customer Relationship Management (CRM) Terhadap Kepuasan Pelanggan di PT Indomobil Trada Nasional Cabang Radin Inten".

Berdasarkan pada latar belakang diatas, maka yang menjadi pokok permasalahan dalam penelitian ini adalah: 1). Bagaimana pengaruh customer relationship management (CRM) terhadap kepuasan pelanggan dilihat dari variabel komunikasi, komitmen dan kualitas jasa di PT Indomobil Trada Nasional Cabang Radin Inten?. 2). Variabel mana dari customer relationship management (CRM) yang paling berpengaruh terhadap kepuasan pelanggan di PT Indomobil Trada Nasional Cabang Radin Inten?

\section{LANDASAN TEORI}

\section{Manajemen Hubungan Pelanggan}

Menurut Kotler dan Keller dalam Iriandini, et all (2015) manajemen hubungan pelanggan adalah proses mengelola informasi rinci tentang pelanggan perorangan dan semua "titik kontak" pelanggan secara seksama untuk memaksimalkan loyalitas pelanggan.

Menurut Brown dalam Tjiptono (2014) manajemen hubungan pelanggan bukan sekedar konsep atau proyek. Namun, manajemen hubungan pelanggan merupakan strategi bisnis yang bertujuan untuk memahami, mengantisipasi, dan mengelola kebutuhan pelanggan organisasi, baik pelanggan saat ini maupun pelanggan potensial. manajemen hubungan pelanggan merupakan dinamika perubahan strategik, proses, organisasional, dan teknis yang dilakukan organisasi dalam rangka mengelola perusahaannya secara lebih baik dan selaras dengan perilaku pelanggan.

Menurut Buttle dalam Tjiptono (2014) konsep manajemen hubungan pelanggan dapat dipahami dalam tiga level yaitu strategik, operasional, dan analitikal. Strategik manajemen hubungan pelanggan berfokus pada pengembangan budaya bisnis yang bersifat customercentric. Budaya semacam ini didedikasikan pada upaya merebut dan mempertahankan pelanggan dengan cara menciptakan dan menyampaikan nilai pelanggan secara lebih efektif dan efisien dibandingkan para pesaingnya. Operasional manajemen hubungan pelanggan berfokus pada otomatisasi proses bisnis dalam kaitannya dengan upaya melayani pelanggan. Berbagai aplikasi perangkat lunak manajemen hubungan pelanggan memudahkan proses otomatisasi pemasaran (seperti segmentasi pasar, manajemen komunikasi pemasaran, dan event-based marketing), penjualan (diantaranya lead management, manajemen kontak pelanggan, dan konfigurasi produk) dan fungsi layanan pelanggan (contohnyaoperasi call centre, web-based service dan field service). Sementara itu, analitikal manajemen hubungan pelanggan berfokus pada pendayagunaan data pelanggan (meliputi data penjualan, catatan pembayaran, respon terhadap kampanye pemasaran, data loyalitas, daya layanan pelanggan, dan sebagainya) untuk meningkatkan customer value dan company value.

Tujuan utama dari manajemen hubungan pelanggan adalah membangun dan mempertahankan basis pelanggan yang memiliki relationship commitment yang kuat serta profitable bagi perusahaan. Melalui manajemen hubungan pelanggan pelanggan akan memiliki ikatan emosional yang berkelanjutan sehingga terjalin hubungan binis yang erat sehingga akan lebih 
mudah dalam meningkatkan kepuasan pelanggan karena apa yang diharapkan dan diingikan pelanggan bisa diketahui (Tjiptono dalam Febrianingtyas, dkk, 2014).

Terdapat empat faktor yang mempengaruhi manajemen hubungan pelanggan, antara lain keuntungan bersama, komitmen, kebenaran dan komunikasi (Robinette dalam Febrianingtyas, dkk, 2013). Adapun dimensi customer relationship management dalam penelitian ini menurut Sorce dan Kotler dalam Iriandini, dkk (2015:4) berdasarkan faktor-faktor yang mempengaruhi manajemen hubungan pelanggan adalah komitmen, komunikasi dan kualitas pelayanan. Berikut ini penjelasan mengenai komitmen, komunikasi dan kualitas pelayanan dalam manajemen hubungan pelanggan : 1). Komitmen; Menurut Jasfar dalam Febrianingtyas, dkk (2014) komitmen adalah rasa saling percaya diantara pihak pihak yang menjalin hubungan, baik secara tersirat (implisit) maupun tidak tersirat (eksplisit) bahwa hubungan mereka akan berlangsung terus menerus dan masing-masing menjaga agar janji mereka tetap terpelihara. Komitmen merupakan orientasi jangka panjang organisasi dengan konsumen terhadap hubungan yang didasarkan pada ikatan emosional dan itikad untuk menjaga hubungan baik agar dapat menghasilkan keuntungan yang lebih tinggi. Komitmen diperlukan oleh suatu organisasi dalam menjalankan manajemen hubungan pelanggan karena dengan adanya komitmen akan membuat pelaksanaan manajemen hubungan pelanggan menjadi lebih diperhatikan dan berkesinambungan. 2). Komunikasi; Komunikasi merupakan salah satu karakteristik fundamental dari sebuah hubungan yang berjalan. Komunikasi yang baik mencermikan jalinan hubungan yang baik. Komunikasi terkait dalam manajemen hubungan pelanggan merupkan pengumpulan informasi antara perusahaan dengan pelanggan. Menurut Lombard dan Plessis dalam Iriandini, dkk (2015:4) mengemukakan bahwa pengumpulan informasi pelanggan dapat dilakukan saat terjadi percakapan atau tanya jawab secara langsung, berfokus pada kelompok pelanggan tertentu dan mengobservasi atau mencari tahu menegenai pmbelian yang dilakukan oleh pelanggan. Menurut Tjiptono dalam Febrianingtyas, dkk (2014:4) untuk mewujudkan komunikasi organisasi yang efektif dibutuhkan lima macam keterampilan pokok yaitu mendengarkan (listening), memberi dan menerima umpan balik (feedback skills), menunjukkan ketegasan (assertiveness), menangani konflik (resolving conflict), serta memecahkan masalah (problem solving). Kelima ketrampilan tersebut diperlukan untuk mewujudkan komunikasi yang ideal antara perusahaan dengan pelanggan sehingga memudahkan dalam menjalankan manajemen hubungan pelanggan. 3). Kualitas pelayanan; Menurut Kotler dan Keller dalam Iriandini, dkk (2015) mejelaskan bahwa kalitas merupakan kunci untuk menciptakan nilai dan kepuasan pelanggan. Kualitas pelayanan menjadi salah satu unsur penting dalam melaksanakan manajemen hubungan pelanggan. Kualitas pelayanan merupakan salah satu senjata dalam memenangkan hati pelanggan sehingga dengan kualitas pelayanan yang efektif dan efisien tentunya akan membuat pelanggan puas dan memudahkan dalam menjalin hubungan yang erat antara organisasi dengan pelanggan.

Menurut Febrianingtyas et al (2014:4) ada beberapa manfaat yang diperoleh dari penerapan relationship marketing antara lain: 1). Adanya penerimaan profit margin dari penjualan di masa depan dan konsumen yang loyal, hal ini sangat berlawanan dengan versi 
paradigma mikro ekonomi yang mengatakan bahwa tidak ada loyalitas konsumen, tidak ada brand equity, tidak ada pembelian ulang, tidak ada komitmen untuk transaksi di masa depan. Setiap pembelian dan penjualan mengasumsikan bahwa masing-masing dimotivasi oleh diri sendiri dan berusaha memaksimumkan kepuasannya melaui transaksi relationship hanya akan merugikan, yang menjadi pengatur adalah harga. Pada kenyataanya loyalitas dapat dibangun jangka panjang. 2). Ada berita dari mulut ke mulut (word of mouth) yang positif dari pelanggan yang terpuaskan dan adanya penjualan dari pihak-pihak lain yang terpengaruh oleh informasi tersebut. 3). Pendekatan ini dapat meningkatkan kualitas pelayanan dan produk karena ada peluang yang cukup besar untuk adanya konfirmasi atas harapan-harapan pelanggan melalui komunikasi, pengalaman pribadi dari perusahaan, berita mulut ke mulut yang positif dan terpenuhinya kebutuhan pribadi. 4). Hubungan baik dalam jangka panjang dapat memungkinkan perusahaan untuk bergerak satu langkah lebih maju dalam perolehan informasi pemasaran yang dapat bermanfaat untuk inovasi maupun pemuasan konsumen secara kompetitif dan proaktif. 5). Jalinan kerjasama jangka panjang juga berpotensi untuk menekan biaya-biaya untuk penelitian pemasaran, biaya penanganan keluhan, dan biaya-biaya untuk menarik minat pembeli melalui taktik promosi.

\section{Kepuasan Pelanggan}

Menurut Kotler dan Keller (2016) kepuasan adalah perasaan senang atau kecewa seseorang yang muncul setelah membandingkan antara persepsi atau kesan terhadap kinerja atau hasil suatu produk dan harapan-harapannya. Jadi, kepuasan merupakan fungsi dari persepsi atau kesan atas kinerja dan harapan. Jika kinerja berada dibawah harapan maka pelanggan tidak puas. Jika kinerja memenuhi harapan maka pelanggan akan puas. Jika kinerja melebihi harapan maka pelanggan akan amat puas atau senang. Kunci untuk menghasikan kesetian pelanggan adalah memberikan manajemen hubungan pelanggan yang tinggi.

Kepuasan pelanggan adalah hasil akumulasi dari konsumen atau pelanggan dalam menggunakan produk dan jasa. Kepuasan pelanggan dapat terwujud karena adanya beberapa faktor yang mempengaruhinya. Faktor yang mempengaruhi kepuasan pelanggan menurut Irawan (2008:37) yaitu kualitas produk, harga, service quality, emotional factor dan kemudahan. Berikut penjelasan dari masing-masing dimensi kepuasan konsumen: 1). Kualitas Produk; Kualitas didefinisikan sebagai keseluruhan ciri serta sifat barang dan jasa yang berpengaruh pada kemampuan memenuhi kebutuhan yang dinyatakan maupun yang tersirat. 2). Harga; Harga adalah jumlah uang (ditambah beberapa produk kalau mungkin) yang dibutuhkan untuk mendapatkan sejumlah kombinasi dari produk dan pelayanannya. Bagi pelanggan yang sensitif biasanya harga murah adalah sumber kepuasan yang penting karena mereka akan mendapatkan value for money yang tinggi. Harga yang rendah menimbulkan persepsi produk tidak berkualitas, sebaliknya harga yang tinggi menimbulkan persepsi produk tersebut berkualitas. 3). Service Quality; Service quality sangat bergantung pada tiga hal, yaitu sistem,teknologi dan manusia. Kualitas jasa adalah sejauh mana jasa tersebut memenuhi spesifikasispesifikasinya. Dimensi kualitas jasa dapat dikelompokan menjadi lima, yaitu bukti fisik, kehandalan, daya tanggap, jaminan dan empati. 4). Emotional Factor; Faktor emosi adalah faktor yang berhubungan dengan gaya hidup dan perasaan seseorang. Emosi adalah 
perasaan yang bergejolak, yang seakanakan menggetarkan dan menggerakkan individu, sehingga hal itu tampak dari luar. Rasa senang, sedih, percaya diri dan bangga merupakan emosional seseorang. 5). Kemudahan; Kemudahan untuk mendapatkan produk atau jasa tersebut. Pelanggan akan semakin puas apabila relatif mudah, nyaman dan efisien dalam mendapatkan produk atau pelayanan.

Strategi kepuasan konsumen menyebabkan para pesaing harus berusaha keras dan memerlukan biaya tinggi dalam usahanya merebut konsumen suatu perusahaan. Yang diperhatikan adalah bahwa strategi kepuasan konsumen merupakan strategi jangka panjang yang membutuhkan komitmen, baik menyangkut dana maupun sumber daya manusia.

Menurut Tjiptono (2001) ada beberapa strategi yang dapat dipadukan untuk meraih dan meningkatkan kepuasan konsumen: 1). Strategi perusahaan berupa Relationship Marketing, yaitu strategi dimana transaksi pertukaran antara pembeli dan penjual berkelanjutan, tidak berakhir setelah penjualan selesai. 2). Strategi Superior Customer Service, yaitu menawarkan pelayanan yang lebih baik daripada pesaing (bentuk-bentuk layanan pelanggan yang meliputi garansi, jaminan, pelatihan cara penggunaan produk, konsultasi teknikal, saran-saran untuk pemakaian produk alternatif, peluang untuk mengembalikan/ menukar produk yang tidak memuaskan, reparasi komponen yang rusak atau cacat, penyediaan suku cadang pengganti, penindak lanjutan kontak dengan pelanggan, informasi berkala dari perusahaan, klub/organisasi pemakai produk, pemantauan dan penyesuaian produk untuk memenuhi perubahan kebutuhan pelanggan, dan lain-lain). 3). Strategi Unconditional Guarantees atau Extraordinary Guarantees. Untuk memberikan kepuasan pada konsumen yang pada gilirannya akan menjadi sumber dinamisme penyempurnaan mutu produk atau jasa dan kinerja perusahaan. Fungsi utama garansi adalah untuk mengurangi resiko konsumen sebelum dan sesudah pembelian barang atau jasa, sekaligus memaksa perusahaan yang bersangkutan untuk memberikan yang terbaik dan meraih loyalitas konsumen, Ada dua bentuk garansi, yaitu : a). Garansi internal, yaitu janji yang dibuat oleh suatu departemen atau divisi kepada konsumen internalnya, contoh : Jaminan dari Divisi Transportasi untuk mengantarkan atau mengambil barang secara tepat waktu bagi divisi lainnya, jaminan dari Divisi Teknik pada suatu distributor komputer untuk menyelesaikan reparasi komputer dengan baik dan cepat, dan lain-lain. b). Garansi eksternal, yaitu jaminan yang dibuat oleh suatu perusahaan kepada para konsumen eksternalnya, yakni mereka yang membeli dan menggunakan produk perusahaan. Contoh : Janji mengantarkan produk secara tepat waktu, garansi bahwa produk berkualitas tinggi, jaminan mendapatkan ganti rugi bila kualitas produk tidak sesuai dengan yang dijanjikan, jaminan potongan harga bila melakukan pembelian ulang di perusahaan yang sama, dan lain-lain. 1). Strategi peningkatan kinerja perusahaan, meliputi berbagai upaya seperti melakukan pemantauan dan pengukuran kepuasan konsumen secara berkesinambungan, memberikan pendidikan dan pelatihan menyangkut komunikasi, salesmanship, dan public relation kepada pihak manajemen dan karyawan, memasukkan unsur kemampuan untuk memuaskan. 2). konsumen ke dalam sistem penilaian prestasi karyawan, dan memberikan empowerment yang lebih besar kepada karyawan dalam melaksanakan tugasnya. 3). Menerapkan Quality Function Deployment (QFD), yaitu untuk merancang suatu proses sebagai 
tanggapan terhadap kebutuhan konsumen. QFD memungkinkan suatu perusahaan untuk memprioritaskan kebutuhan konsumen, menemukan tanggapan inovatif terhadap kebutuhan tersebut, dan memperbaiki proses hingga tercapai efektivitas maksimum.

\section{METODE PENELITIAN}

Jenis penelitian yang digunakan dalam penelitian ini adalah penelitian asosiatif dengan menggunakan pendekatan kuantitatif. Penelitian ini bertujuan untuk melihat pengaruh masingmasing variabel dari customer relationship management, yaitu variabel komunikasi, komitmen dan kualitas jasa terhadap kepuasan konsumen.

Populasi dalam penelitian ini adalah pelanggan yang melakukan perawatan/servis mobil di bengkel resmi Nissan Radin Inten. Teknik pengambilan sampel dalam penelitian ini ditentukan dengan menggunakan teknik nonprobability sampling yaitu dengan purposive sampling dimana respondenya adalah pelanggan yang melakukan perawatan/servis mobil di bengkel resmi Nissan Radin Inten minimal 3 bulan terakhir dengan jumlah responden sebanyak 120 orang.

Analisis data yang digunakan dalam penelitian ini adalah analisis regresi linier berganda. Analisis ini digunakan bila peneliti bermaksud melihat hubungan atau pengaruh antara variabel independen dengan variabel dependen atau meramalkan bagaimana keadaan (naikturunnya) variabel dependen, bila dua atau lebih variabel independen sebagai faktor prediktor dimanipulasi (dinaikturunkan). Jadi analisis regresi linier berganda akan dilakukan bila jumlah variabel independennya minimal 2 . Persamaan regresi untuk tiga prediktor adalah:

$$
Y=a+b_{1} X_{1}+b_{2} X_{2}+b_{3} X_{3}+e
$$

Keterangan :

$\mathrm{Y}=$ Kepuasan Konsumen

$\mathrm{a}=$ Nilai konstanta

$\mathrm{X} 1=$ Komitmen

$\mathrm{X} 2=$ Komunikasi

X3 = Kualitas pelayanan

b1 = Koefisien komitmen

b2 = Koefisien komunikasi

b3 = Koefisien kualitas pelayanan

\section{HASIL PENELITIAN DAN PEMBAHASAN}

Pada penelitian ini untuk mengetahui besarnya pengaruh variabel manajemen hubungan pelanggan (X) terhadap variabel kepuasan pelanggan (Y). Hasil yang diperoleh sebagai berikut:

Koefisien determinasi $\left(\mathrm{R}^{2}\right)$ sebesar 0,870 yang berarti bahwa sebesar $87,0 \%$ kepuasan konsumen dapat dijelaskan dengan menggunakan variabel manajemen hubungan pelanggan sedangkan sisanya yaitu $13, \%$ dapat disumbangkan oleh variabel lain yang tidak diteliti.

Variabel manajemen hubungan pelanggan yang paling mempengaruhi kepuasan pelanggan adalah atribut komunikasi dimana pengaruhnya sebesar 0,550 atau sebesar $55 \%$ mempengaruhi variabel kepuasan pelanggan.

Diketahui terdapat 3 model regresi yang terbentuk. Dilihat dari nilai sig. masing-masing model diketahui sebesar $0,000<$ dari taraf signifikansi 0,05 . Dengan demikian variabel manajemen hubungan pelanggan melalui dimensidimensinya (komunikasi, komitmen, dan kualitas jasa) memiliki pengaruh yang nyata (siginifikan) terhadap kepuasan konsumen.

Customer relationship management (CRM) terhadap kepuasan pelanggan dilihat dari masing-masing nilai sig. 
dimensinya memiliki angka yang lebih kecil dari taraf signifikansi $5 \%$ atau 0,000 $<0,05$. Sehingga, hal ini menunjukkan bahwa customer relationship management berpengaruh secara signifikan terhadap kepuasan pelanggan.

Persamaan regresi yang terbentuk adalah $\mathrm{Y}=5,515+1,306 \mathrm{X}_{1}+1,204 \mathrm{X}_{2}+$ $1,175 \mathrm{X}_{3}$. Dari persamaan tersebut dapat disimpulkan bahwa pengaruh customer relationship management (CRM) memiliki pengaruh dengan arah yang positif (searah) terhadap kepuasan konsumen, dimana apabila pelaksanaan CRM dilakukan dengan baik dan benar (meningkat), maka konsumen akan memiliki kepuasan yang tinggi (kepuasan konsumen meningkat).

\section{KESIMPULAN DAN SARAN}

Kesimpulan hasil penelitian dan pembahasan pada bab sebelumnya, maka dapat disimpulkan sebagai berikut: 1). Setelah dilakuak uji hipotesis (uji F) signifikan dari variabel-variabel independen atas customer relationship management yaitu komunikasi, komitmen dan kualitas jasa terhadap kepuasan konsumen atas layanan Nissan Radin Inten. 2). Dari hasil analisis regresi dengan menggunakan metode stepwise, diketahui bahwa atribut dari customer relationship management (CRM) yang memiliki pengaruh terbesar atas kepuasan pelanggan adalah komunikasi.

Saran yang dapat disampaikan kepada perusahaan Nissan Radin Inten adalah agar terus menjaga serta meningkatkan kegiatan CRM yang baik kepada pelanggan khususnya dalam hal komunikasi sehingga diharapkan apa yang diinginkan oleh pelanggan dapat terlaksana dan terpenuhi dengan baik demi menjaga kepuasan pelanggan.

\section{DAFTAR PUSTAKA}

Buchari, Alma.2014. Manajemen Pemasaran dan Pemasaran Jasa. Bandung: CV Alfabeta.

Febrianingtyas, Media, Suharyono dan Edy Yulianto. 2014. Pengaruh Customer Relationship Management (CRM) Terhadap Kepuasan dan Loyalitas Pelanggan (Survei pada Nasabah Bank Jawa Timur Cabang Gedung Inbis Malang). Jurnal Administrasi Bisnis

Gaikindo. Indonesian Automotive Idustry

Data. Melalui

http://files.gaikindo.or.id//. $(16 / 10 / 17)$

Ghozali, Imam. 2016. Aplikasi Analisis Multivariete dengan Program IBM SPSS 23. Edisi Kedelapan. Semarang : Badan Penerbit Universitas Diponegoro.

Irawan, Handi. 2008. Prinsip Kepuasan Pelanggan. Jakarta : Elex Media Komputindo

Iriandini, Anggita Putri, Edy Yulianto dan M. Kholid Mawardi. 2015. Pengaruh Customer Relationship Management (CRM) Terhadap Kepuasan dan Loyalitas Pelanggan (Survei pada Pelanggan PT Gemilang Libra Logistics Kota Surabaya). Jurnal Administrasi Bisnis

Komalasari, Eka. 2014. Pengaruh Customer Relationship Management Terhadap Kepuasan Nasabah pada PT Bank Riau Kepri Cabang Utama Pekanbaru. Jurnal ISSN

Kotler, Philip \& Kevin Lane Keller. 2016. Manajemen Pemasaran. Edisi 12. Jilid 1. Jakarta : PT Indeks

Lovelock, Christoper dan Jochen Wirtz. 2011. Service Marketing. New Jersey.USA : Pearson. 2013. Pemasaran Jasa: Manusia, Teknologi, dan Strategi (Perspektif Indonesia). Jakarta : Erlangga. 
Lupiyoadi, Rambat. 2014. Manajemen Pemasaran Jasa. Jakarta : Salemba Empat

Ningsih, Nina Wachyu, Suharyono dan Edy Yulianto. 2016. Pengaruh Customer Relationship Management (CRM) Terhadap Kepuasan dan Loyalitas Pelanggan (Survei pada Pelanggan PT Astra Internasional Tbk-TSO AUTO 2000 Cabang Denpasar). Jurnal Administrasi Bisnis.

Nissan Radin Inten. 2017. Work Order Mei-Juli 2017: Dealer Management System.

Ratnasari, Ririn Tri dan Mastuti H. Aksa. 2016. Manajemen Pemasaran Jasa. Bogor: Ghalia Indonesia.

Sangaji, Mamang, Etta dan Sopiah. 2010. Metodologi Penelitian. Yogayakarta : ANDI

Setyaleksana, Bony Yosua, Suharyono dan Edy Yulianto. 2017. Pengaruh Customer Relationship Management (CRM) Terhadap Kepuasan dan Loyalitas Pelanggan (Survei pada Pelanggan GraPARI Telkomsel di Kota Malang). Jurnal Administrasi Bisnis

Sugiyono. 2010. Metode Penelitian Kuantitatif Kualitatif $R \quad \& \quad D$. Bandung : Alfabeta

Sunyoto, Danang. 2014. Dasar-Dasar Manajemen Pemasaran. Jakarta : CAPS

Swasta, Basu dan Hani Handoko. 2010. Manajemen Pemasaran: Analisa dan Perilaku Konsumen. Yogyakarta : BPFE

Tjiptono, Fandy dan Gregorius Chandra. 2016. Service, Quality dan Satisfaction. Yogyakarta: ANDI 2014. Pemasaran Jasa.

Yogyakarta : ANDI . 2001. Pemasaran Jasa.

Yogyakarta : ANDI

Vanessa, Gafar. 2007. Customer Relationship Management and
Marketing Public Relation.

Bandung : Alfabeta

http://www.jdpower.com/press-

releases/2016-indonesia-customer-

service-index-csi-study

https://www.bps.com

https://www.kompasiana.com/arielarrayya n/5500c26ca333112370511e98/kendaraan -pribadi-kebutuhan-atau-gaya-hidup https://www.nissan.co.id/find-adealer.html. 